\title{
Where Transit Use Is Growing: Surprising Results
}

\author{
Gregory L. Thompson, Jeffrey R. Brown, Rupa Sharma, and Samuel Scheib \\ Florida State University
}

\begin{abstract}
This article investigates whether transit's fate is tied to the last vestiges of old urban forms or whether transit is finding niches in the new, largely suburban urban forms that increasingly have manifested themselves since the 1920s. The hypothesis is that most growth is in census regions with the strongest vestiges of older urban forms centered on CBDs. The hypothesis was tested by documenting how transit performance changed between 1990 and 2000 in U.S. metropolitan areas with more than 500,000 people in the year 2000. Results show that, for MSAs with fewer than 5 million people, transit use has been growing faster than very rapid population growth in the West region, but not elsewhere in the country. The conclusion is that transit growth is not tied to old urban forms. A future article will explore causality of transit use growth and service productivity change.
\end{abstract}

\section{Introduction}

This article documents changes in the magnitude of transit service, use, and productivity in U.S. metropolitan areas during the 1990s. We include transit and population variables for all metropolitan statistical areas (MSAs) and consolidated metropolitan statistical areas (CMSAs) with a year 2000 population greater than 500,000 people. Our purpose is to determine whether regional variations in service and usage exist for MSAs and CMSAs in different population size categories. 
This exploration is prompted by earlier work suggesting that transit use per capita may be increasing in rapidly growing parts of the country, contrary to the commonly held belief that transit demand exists primarily in older industrial-era cities (Thompson and Matoff 2003). The earlier work was based on transit performance in only nine MSAs and prompted a desire for a more systematic documentation of transit trends, whose relationships ultimately would be analyzed statistically. The statistical analysis does not occur in this article, which describes regional and size category trends that suggest transit use and productivity are developing in ways very different from commonly held perceptions.

\section{Relationships among Urban Form, Travel Patterns, and Transit Performance}

The national decline in transit share is well studied. Specifically, Pisarski's (1996) analysis of the census's journey to work questions for 1970, 1980, and 1990 documents suburbanization of jobs as well as residents, the rise of two-worker households, the ever-increasing use of single-occupant autos, and declines in the share of travel of all other transportation modes, including public transportation. Pisarski found that the greatest absolute declines in transit work-trip mode split occurred in central cities, but greater relative declines occurred in suburban rings. The implication is that, while transit does not do well in any urban environment, it does least well in the suburbs. However, he does note several anomalies, including Houston, Los Angeles, New York, Orlando, Philadelphia, Phoenix, Rochester, San Diego, and Tampa.

Pucher and Renne's (2003) analysis of the National Household Travel Survey (NHTS) allows for inferences about characteristics of transit demand only at the U.S. Census-defined region level, due to NHTS sample size. They note that the proportion of travelers using transit for all trip purposes (not just work trips) is larger in the East and Midwest than in other regions of the country, though there is some strength in the West. They infer that transit demand is greatest in those urban regions that experienced much of their growth when transit was the dominant mode of urban transportation, generally before the late 1920 s.

Both Pisarski and Pucher and Renne conclude that, while transit use is tiny and declining, it is highest in urban structures tied to the past rather than the future. That is, it is tied to central business districts (CBDs) and dense older (streetcar) suburban areas rather than to the modern suburbs. Such thinking is encapsulated 
in the often-cited work of Pushkarev and Zupan (1977, 1980), though Cervero and Seskin (1995) raise questions about the interpretation. If true, it seems likely that as the forces of decentralization further erode these old urban structures, remaining transit use will completely slip away.

We are skeptical, however, of the notion that transit's fate is tied to the old urban forms. Tantalizing evidence suggests transit might have a niche in auto-dominated suburban areas that are rapidly developing. Pisarski's anomalies imply this. Work by Thompson and Matoff (2003), which documents transit performance in nine metropolitan regions, also supports this theory. While the Thompson and Matoff work is not comprehensive in its choice of metropolitan regions, it shows that there are metropolitan regions with transit growth. The regions in their study are not where old urban forms remain influential but regions characterized by rapid population and employment growth, mostly in the suburbs. In some cases, they are regions with very weak CBDs where transit use has been relatively low.

\section{Methodology}

Transit performance in urban regions varies by population size (Downs 2004; Pucher 2004). To control for population size, we assigned each of the $81 \mathrm{MSAs}$ and CMSAs with more than 500,000 persons to one of four size categories: 500,000 to 1 million people (small MSAs), 1 million to 5 million people (medium MSAs), 5 million to 10 million people (large MSAs), and greater than 10 million people (mega MSAs). To explore regional variation (our proxy for old versus new urban forms), we organized each size category by census region (Northeast, Midwest, South, and West). Table 1 shows the distribution of MSAs in each category based on population and region. We then calculated performance statistics for the aggregated transit service in each MSA. Finally, we reported the median values of each statistic in each category.

The methodology ties together two databases, the National Transit Database (NTD) and the U.S. Census (U.S. Census Bureau 2000, 2003). The NTD, which we accessed using the Florida Department of Transportation's Florida Transit Information System (FTIS), provides information on system performance by transit agency for all agencies that received federal aid (FDOT 2004). We identified all transit agencies operating in each MSA or CMSA in the study and aggregated their performance statistics. Our approach to examining transit performance thus 
Table 1. Distribution of MSAs by Region

\begin{tabular}{lcccc}
\hline $\begin{array}{l}\text { Census-Defined Geographic } \\
\text { Region }\end{array}$ & $\begin{array}{c}\text { Mega } \\
\text { MSAs }\end{array}$ & $\begin{array}{c}\text { Large } \\
\text { MSAs }\end{array}$ & $\begin{array}{c}\text { Medium } \\
\text { MSAs }\end{array}$ & $\begin{array}{c}\text { Small } \\
\text { MSAs }\end{array}$ \\
\hline Midwest & & 2 & 9 & 6 \\
Northeast & 1 & 2 & 5 & 6 \\
South & & 2 & 18 & 13 \\
West & 1 & 1 & 8 & 7 \\
Total & 2 & 7 & 40 & 32 \\
\hline
\end{tabular}

differs considerably from the often-cited study by Hartgen and Kinnamon (1999), who conduct system-specific evaluations.

The choice of the MSA or CMSA as the unit for analysis is based on the need to avoid misattribution of the population responsible for generating transit patronage. In the NTD, patronage and other transit statistics are readily available only for entire transit systems. In calculating such performance measures as passenger miles per capita or vehicle miles per capita, we found it necessary to identify the population associated with the service and ridership. Too much population is attributed to a transit system if the service area of the system does not fill up most of the area for which population is counted; too little is attributed if transit systems spill over into adjoining population areas. Figure 1 shows such situations.

\section{Figure 1. Transit Service Provision in a Hypothetical Urban Region}

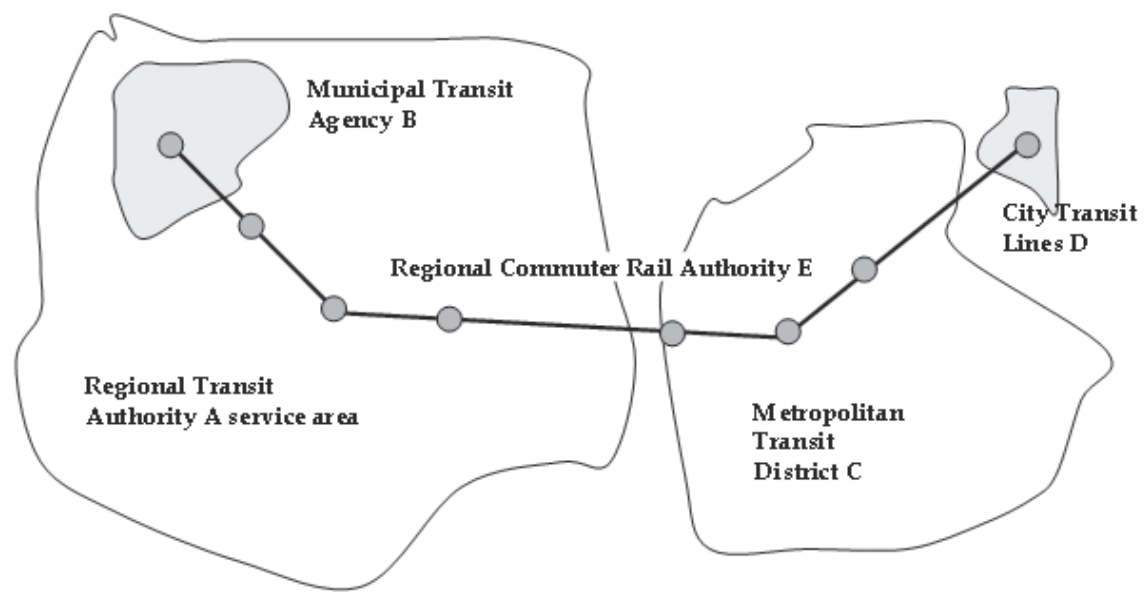


Difficulties in correctly attributing population to transit statistics also occur when more than one transit system serves the same population. The propensity of the population to use transit is spread over the two or more transit systems serving it, so to understand how much ridership the population produces, we must aggregate ridership for all of the relevant transit systems. Figure 1 shows two MSAs that have grown together and that are served by several transit systems exhibiting all of these problems. A solution to overcoming the problems is to aggregate performance indicators for all transit operators in the smallest geographic area containing all of the services. In Figure 1, this is the CMSA, but if the commuter rail authority did not exist, the aggregation could be for each of the two MSAs.

\section{Choice of Performance Measures}

Our goal in comparing transit systems is to assess trends in demand, supply, and productivity, using commonly accepted measures of transit performance. Because MSAs vary in population, even within the population groups that we defined, we need to express demand and supply on a per capita basis. We use passenger miles per capita for demand and vehicle miles per capita for supply. We also determine trends in productivity of transit service between different urban regions. Fielding (1987) identified several measures of productivity: pairwise combinations of resources that transit systems consume, service they provide, and the degree to which that service is consumed. Typical measures are operating expense per vehicle mile, passenger miles per vehicle mile, and operating expense per passenger mile (Fielding 1987). We do not focus on managerial practices that affect the cost of providing vehicle hours or miles, an important topic that merits a different article, but instead focus on the productivity of each vehicle mile operated. Are there regional differences here? Is transit service in rapidly growing, auto-oriented metropolitan areas less productive than that in denser, more stable urban areas? Trends in passenger miles per vehicle mile (load factor) will tell us.

We do not show cost per passenger mile, primarily because it is a composite variable that results from dividing the cost of operating a vehicle one mile by its productivity. As we are addressing the productivity issue, the remaining insight resulting from cost per passenger mile comes from the cost of operating a vehicle one mile. Many variables affect this, such a labor contracts, congestion levels, and percent of service provided by rail to name just three, and these vary in unpredictable ways from one metropolitan area to another. We cannot interpret cost per passenger miles in terms of changing urban form. Thus, we do not include it. 


\section{Results}

We examined transit performance by grouping the 81 MSAs and CMSAs with more than 500,000 people by population size and organizing these groups by census region. Results for each MSA population group are presented below.

\section{Transit Performance in Mega MSAs}

The dataset contains two mega MSAs (population greater than 10 million), one (the Los Angeles-Riverside-Orange County, California CMSA) is located in the West region; the other (the New York-Northern New Jersey-Long Island, New York New Jersey Connecticut Pennsylvania CMSA) is located in the Northeast. The dataset is compared in Table 2.

Transit was far more important for the New York region on almost every dimension in 1990, though the magnitude of transit change between 1990 and 2000 was more comparable. In 1990, the New York region supported almost four times as many transit service miles per capita as did the Los Angeles region while more than five times as many passenger miles per capita made use of transit in the New York region. In 1990, each mile of transit service in New York carried nearly 50 percent more passengers than that in Los Angeles.

Between 1990 and 2000, the New York region hardly expanded transit service, while the Los Angeles region expanded transit service miles by 23 percent per capita, reflecting in part the introduction of a subway line and a far-flung system of commuter trains while expanding light rail transit service that was begun the previous decade. Transit usage per capita increased in the Los Angeles region by about 11 percent, less than half the increase in service. Usage also increased by about 11 percent in the New York region, even though there was negligible service growth. Accordingly, over the decade, transit in the New York region became more productive while it became less productive in the Los Angeles region. These developments occurred despite the fact that the Los Angeles region is the densest MSA in the country. Comparison of the two mega MSAs supports the hypothesis that transit performs best in regions with traditional urban forms.

\section{Transit Performance in Large MSAs}

The dataset contains seven large MSAs (population between 5 million and 10 million). One of the four regions (West) contained one large MSA, and three regions (Midwest, Northeast, and South) each had two. Median populations in 2000 ranged from 6,003,782 to 7,306,984. Table 3 shows that service provision in 1990 varied with the Northeast and West grouped at the high end and the South and 


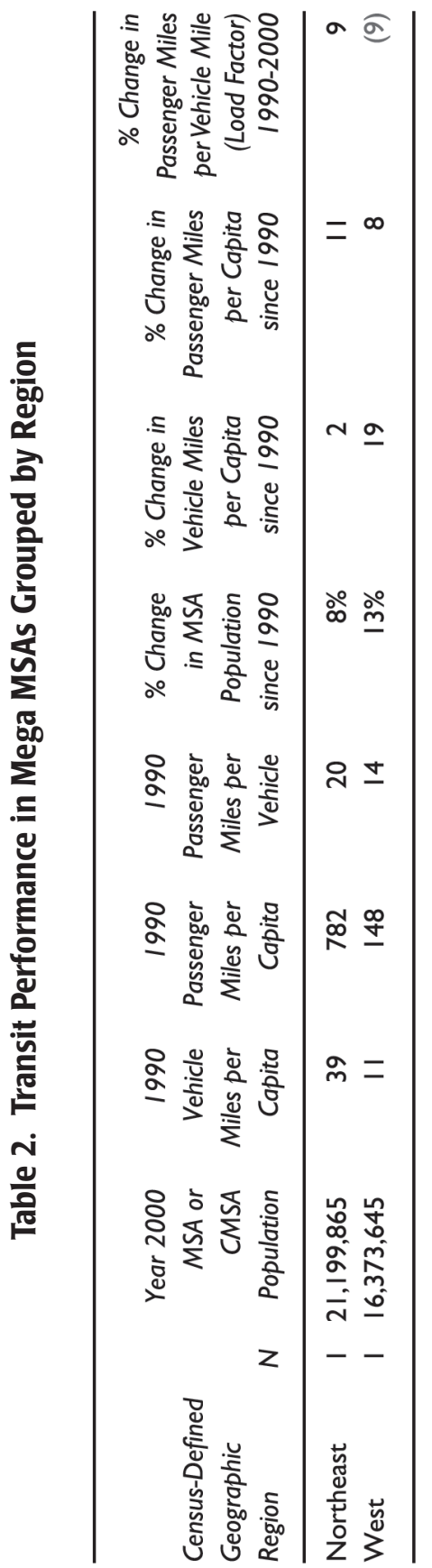

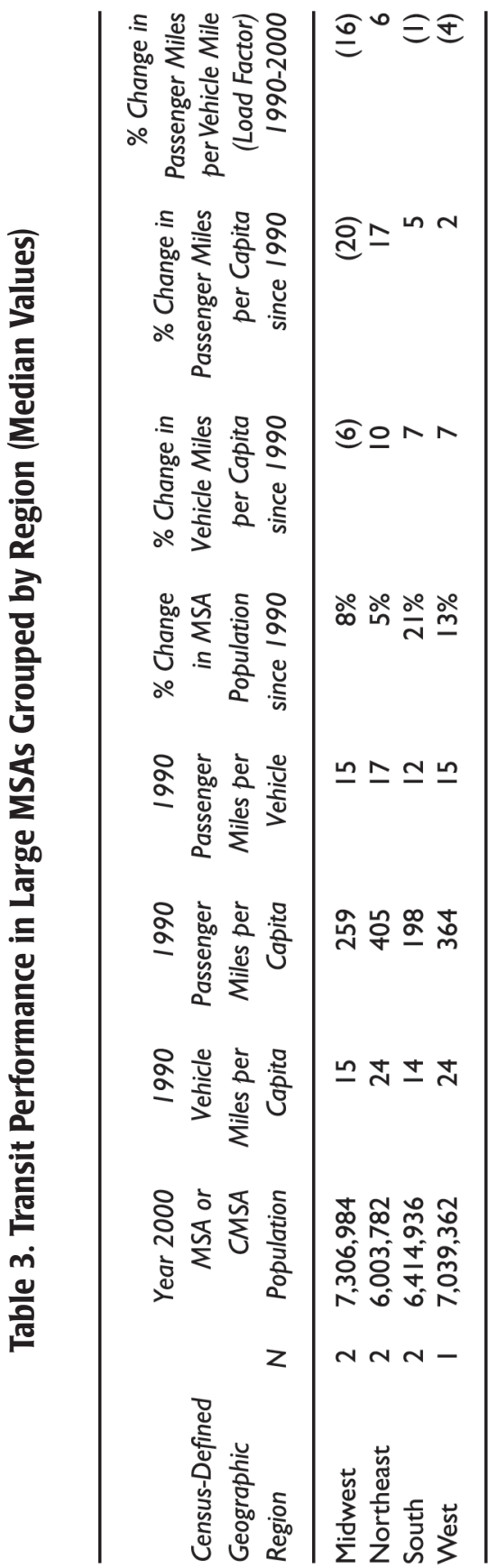


Midwest at the low end. This pattern also prevailed for 1990 passenger miles per capita. Productivity was about the same in the Northeast, Midwest, and West, and somewhat lower in the South.

Patterns of growth and decline in the 1990s varied more widely between the four regions. In three of the four regions, service increased faster than population between 1990 and 2000 in the median MSA. In three of the four regions, ridership also increased faster than population between 1990 and 2000 in the median MSA. The Northeast region experienced the largest gains in service per capita and ridership per capita. In the Midwest region, service and ridership failed to keep pace with modest population increases. Only in the Northeast region did productivity improve between 1990 and 2000 in the median MSA. In the other regions, ridership change failed to keep pace with service change, and thus productivity declined.

Overall, the performance of transit in large MSAs constitutes mixed evidence about the hypothesis that transit is performing best in metropolitan areas that are the more traditional in nature. The large MSA in the West region, which provided a high level of service per capita in 1990, is the San Francisco CMSA. The San Francisco CMSA does, in fact, contain a strong CBD and high population densities surrounding it, but most of the growth in transit service in the San Francisco CMSA during the 1990s was in suburban areas, and that growth has attracted usage. Much the same can be said for the Boston region, one of the two MSAs in this category in the Northeast region.

The huge productivity increase in the Northeast largely reflected growth of commuter rail service in the Boston area. Boston's commuter rail ridership rose by 105 percent during the decade, far outstripping the 57 percent increase in commuter rail vehicle miles. Bus passenger miles rose by 21 percent in Boston, again faster than the 8 percent increase in bus vehicle miles. These changes tend to support the view that transit works well connecting distant suburban commuters with strong CBDs, which the Boston area has.

Dallas was the only other metropolitan area in the large-sized category to experience productivity improvement, though the increase occurred on top of a low base. Dallas also was the MSA area in the large-sized category whose population grew the most rapidly, and it achieved its productivity improvement on top of a very large service expansion that outpaced population growth. The Dallas experience supports the idea that transit can do well in suburban-based environments. 
On the other hand, Dallas's productivity growth was only slightly ahead of productivity change in the Chicago area, which is a much more traditionally structured metropolitan area experiencing slow growth. Chicago enjoyed the second highest degree of transit service and use in the United States in 1990. While Chicago cut back service by 8 percent during the 1990s, usage also fell by 8 percent, resulting in no change in productivity. Chicago suggests that a well-managed transit system can hold its own in a slow-growth traditional urban environment.

\section{Transit Performance in Medium-Sized MSAs}

The 40 MSAs in the category account for roughly one half of the MSAs in the study. Of the 40 medium-size MSAs, just under half (18 out of 40 ) are in the South region (see Table 1). Nine medium-size MSAs are in the Midwest, 8 are in the West, and 5 are in the Northeast. Outside of the Midwest and Northeast regions, most of the growth of the MSAs in this category took place during the auto era after World War II.

Medium-size MSAs tended to provide less service per capita than did large-size MSAs, and there was less variation in service provided across the regions of the country in 1990, as shown in Table 4. Aside from the West region, whose median MSA in this category provided 12 service miles per capita, service was uniform, ranging from 7 to 8 vehicle miles per capita. Service usage also was more uniform, ranging from 9 to 10 passenger miles per service mile. Usage per capita ranged from 49 to 108 passenger miles per capita. Usage was highest in the West where the median MSA had 108 passenger miles per capita in 1990, while at the other end of the spectrum, the South attracted only 49 passenger miles per capita.

During the 1990s, the West's lead in passenger miles per capita grew substantially. Figure 2 shows that only in the West did patronage growth outpace population growth between 1990 and 2000. Figure 3 shows that MSAs in all four regions increased service faster than they added population. Figures 2 and 3 are boxplots that show the distribution of observations for patronage change and service change respectively. The boxes in the plot cover the distance between the upper and lower quartiles of the observations, and the line in the box denotes the median observation. Outliers are marked with an asterisk. The figures clearly show that the median MSA in all four regions increased service faster than they added passengers. The decline in productivity was much less severe in the West region than elsewhere. In the median MSA in the West, the ratio of passenger miles to vehicle miles declined by a mere 3 percent between 1990 and 2000, as compared to declines of 18 percent in the Northeast, 17 percent in the South, and 10 percent 


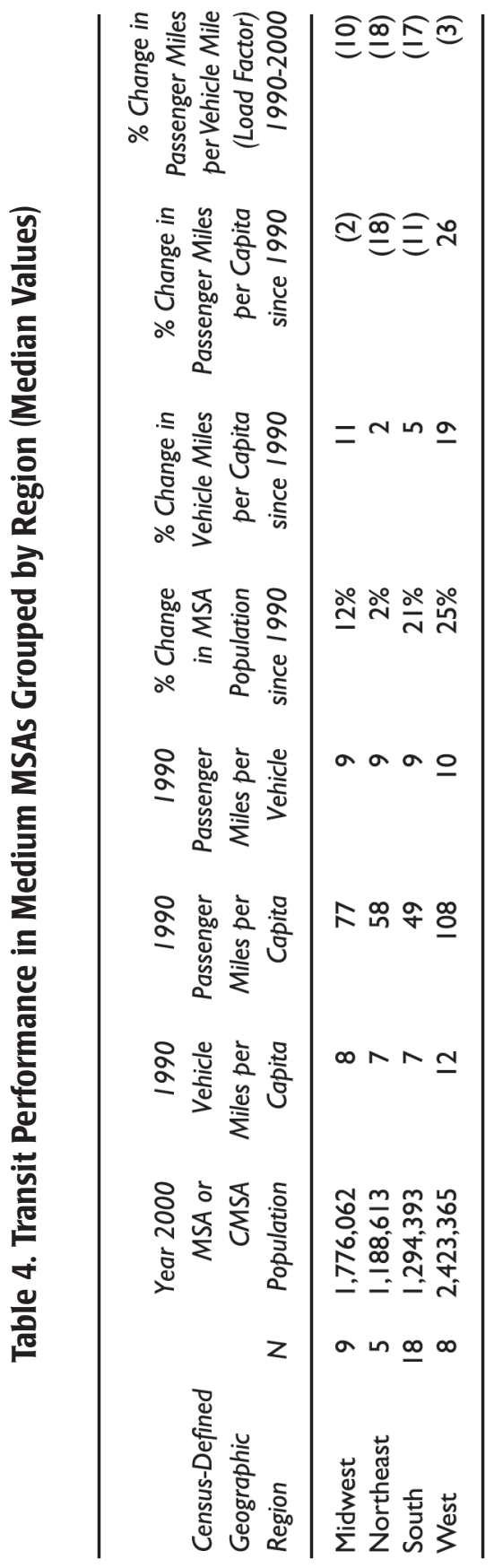


in the Midwest. In an era of rapidly declining service productivity, the West region MSAs nearly held their ground.

Figure 2. Percent Change in Passenger Miles per Capita for Medium MSAs (Medium MSAs: 1 million to 5 million people)

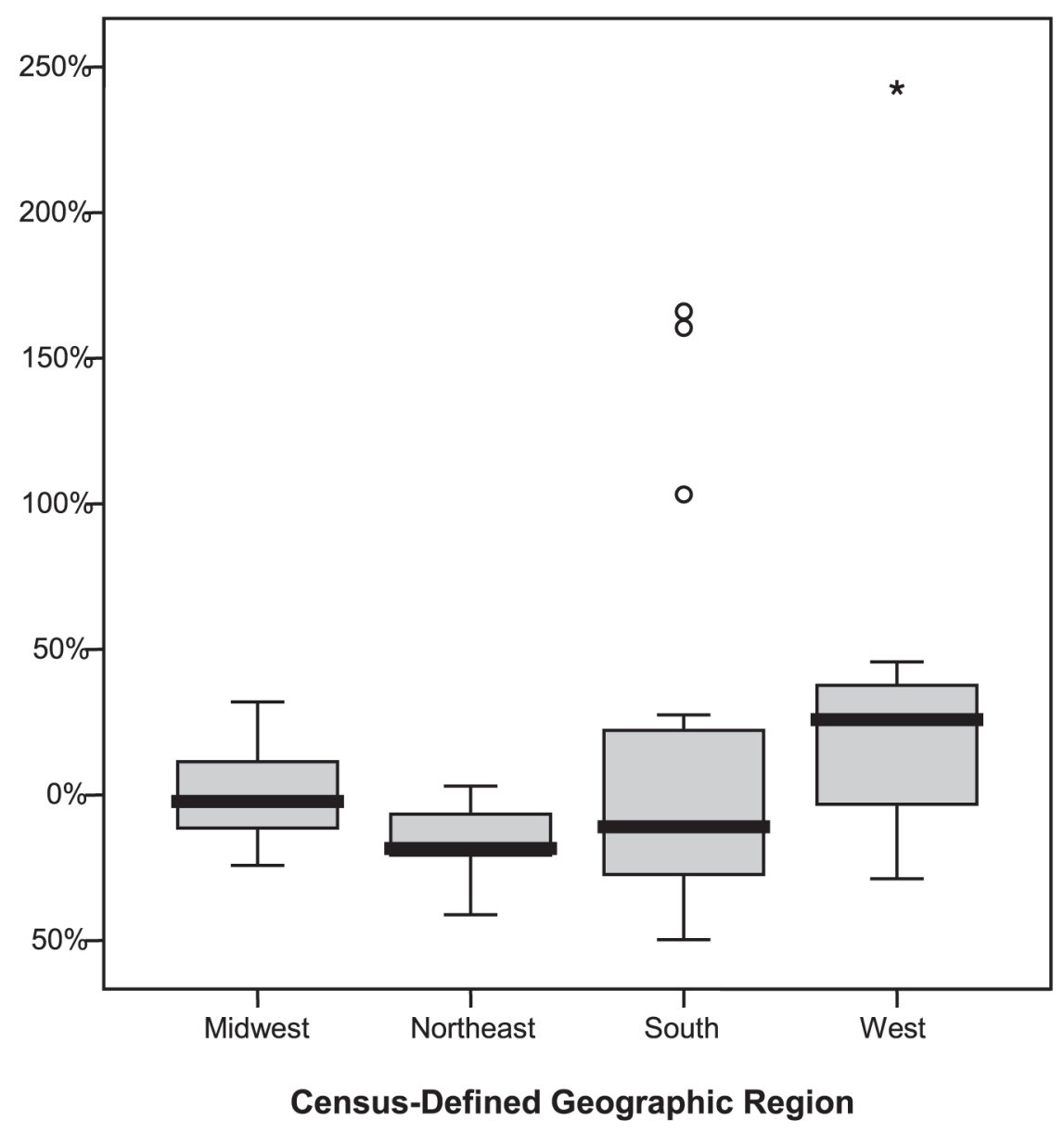


Figure 3. Percent Change in Vehicle Miles per Capita for Medium MSAs (Medium MSAs: 1 million to 5 million people)

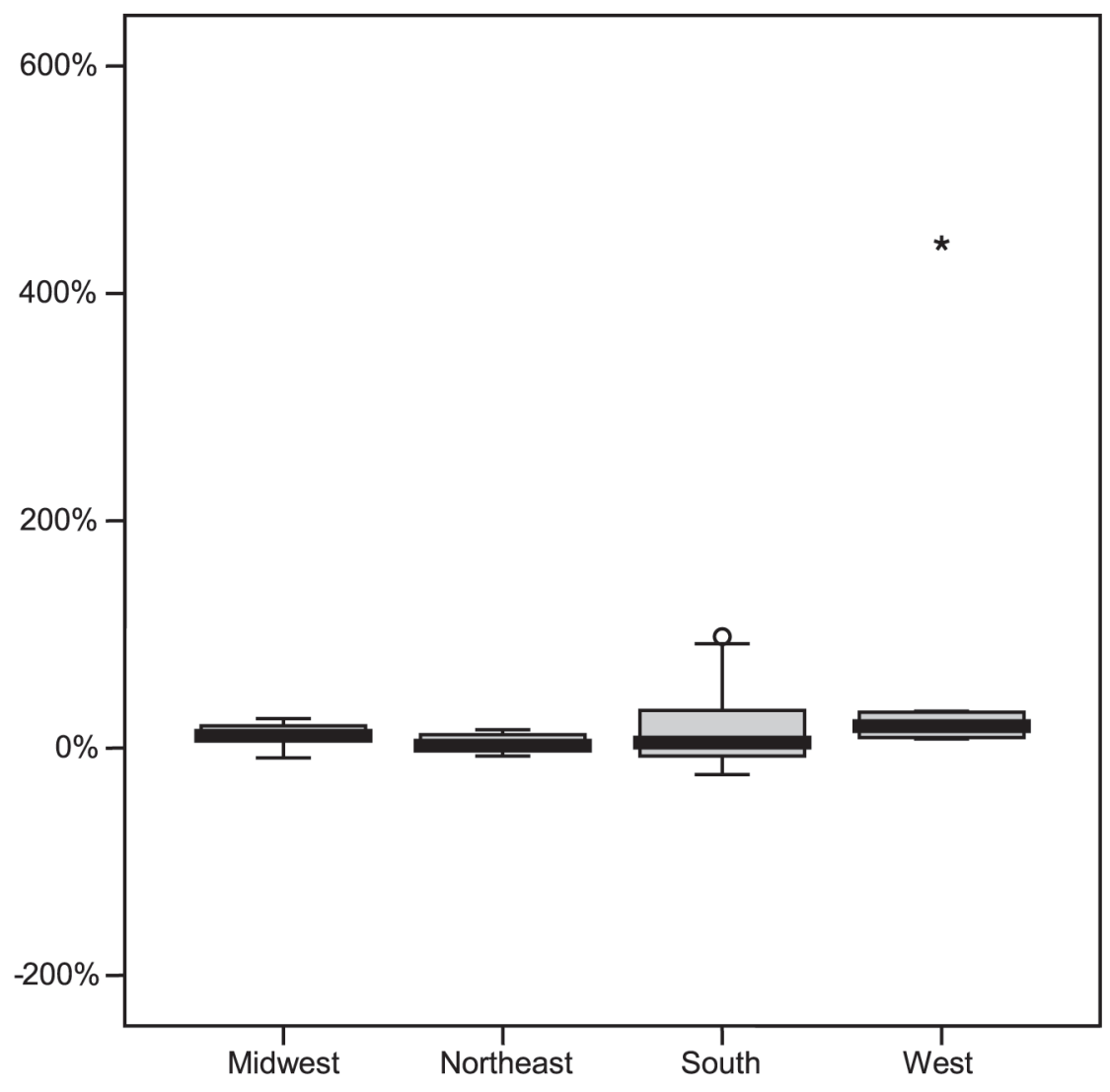

Census-Defined Geographic Region

These results do not support the hypothesis that transit investments are most effective only in regions of the country characterized by older urban forms. Some MSAs with industrial-era legacies, such as St. Louis, saw their transit service and usage grow substantially during the 1990s. But transit service and usage in many other such MSAs did not grow. More typically, transit service and usage grew in rapidly growing western and mountain sunbelt urban regions. One of these, Portland, is famous for coordinating development with transit, and that policy may be partly responsible for transit growth in the Portland urban region. Most other urban areas with rapidly growing transit usage in the West region do not 
have such land-use controls in place, however. What accounts for the superior transit performance of the medium-sized category is not known at this time, but because of the rapid population growth of medium-sized MSAs in this region, the prevalence of urban structure dating from before the 1930s does not appear to be among the causes. In general, rapidly growing medium-sized MSAs in the South did not experience improving transit performance, so growth alone also is not an adequate explanation, but there were mid-sized cases in the South where transit's performance did improve substantially (Norfolk-Virginia Beach, Orlando, West Palm Beach).

\section{Transit Performance in Small-Sized MSAs}

There are 32 small-sized MSAs spread throughout the country, as shown in Table 5. The small-sized MSAs supplied significantly less transit service per capita than their medium-sized counterparts, as a comparison of Tables 4 and 5 shows. In 1990, the median small-sized MSA in the four regions supplied between 4 and 6 service miles per capita. Small-sized urban areas in the South and West provided service close to the low end of the scale; the Northeast and Midwest provided service levels toward the top end of the range. Productivity of each service mile, which ranged from 5 to 7 passenger miles per service mile, also was much lower than in the medium-sized MSAs. Consequently, transit usage, which ranged from 23 passenger miles per capita for the South to 39 passenger miles per capita for the Northeast, was lower as well.

Between 1990 and 2000, the population of the small MSAs grew rapidly in two regions (South and West). Unlike in the medium-sized MSAs, transit service in the small MSA category generally did not grow as fast as population (see Figure 4). The exception was the West region, where transit service in the median small-sized MSA increased 6 percent more than the MSA's 22 percent increase in population. In the Midwest region, by contrast, population change far outpaced service change. 


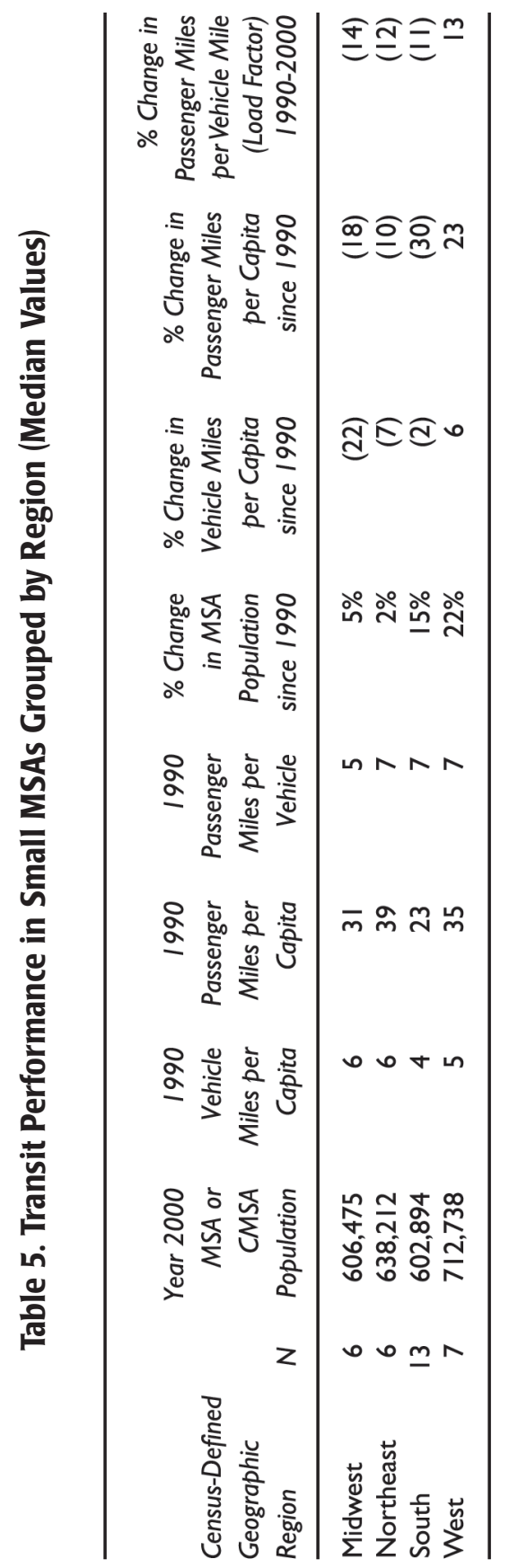


Figure 4. Percent Change in Vehicle Miles per Capita for Small MSAs (Small MSAs: 500,000 to 1 million people)

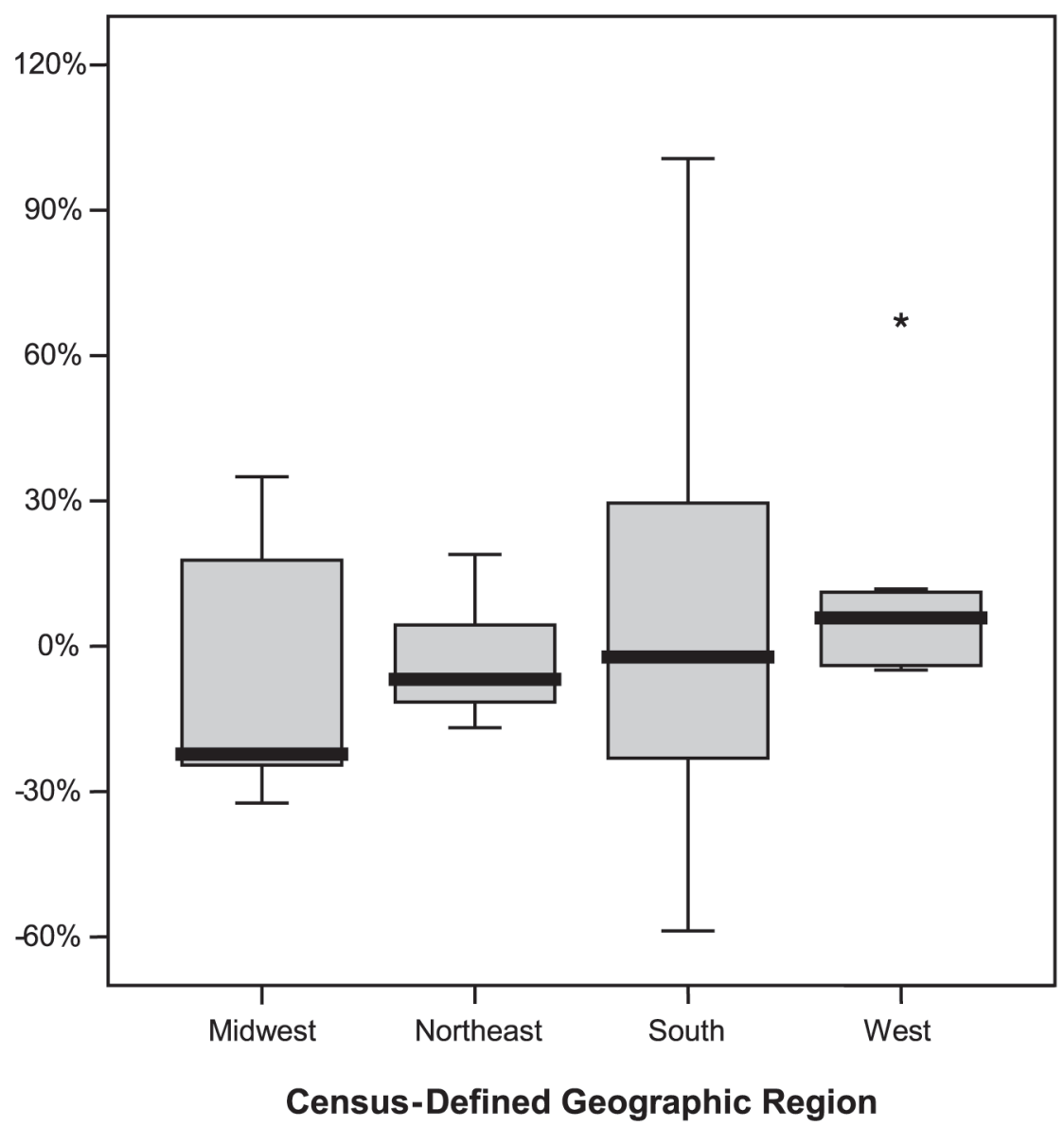

Passenger miles per capita increased by 23 percent during the decade for smallsized MSAs in the West region, coming on top of a 22 percent population increase (see Figure 5). The median small-sized MSA in each of the other regions posted substantial declines in passenger miles per capita, though there was an exception in Florida (Sarasota). Productivity also improved for small-sized MSAs in the West region, but not in the other regions. 
Figure 5. Percent Change in Passenger Miles per Capita for Small MSAs (Small MSAs: 500,000 to 1 million people)

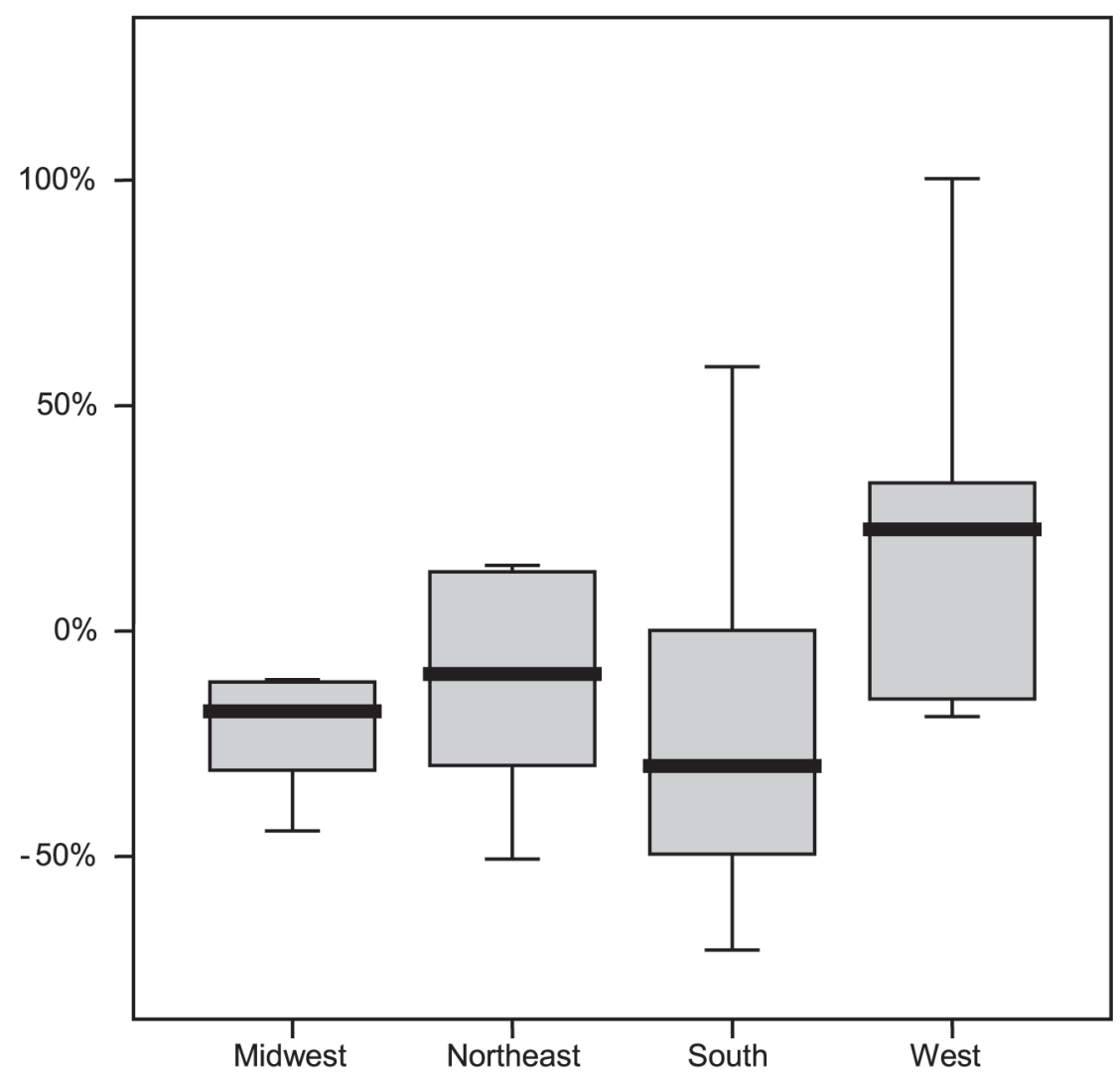

Census-Defined Geographic Region

Results for small-sized MSAs generally refute the hypothesis that transit performs best in cities of old urban form. As in the case of medium-sized MSAs, the smallsized MSAs with the better-performing transit service generally were those in the rapidly growing West. In the South, service and productivity change are not pacing the growth in population. The notable exception is Sarasota, Florida. 


\section{Conclusions}

Our hypothesis was that growth in transit use per capita and increasing transit productivity is associated with old urban forms. We assumed that urban areas having such characteristics would most likely be located in the Northeast and Midwest regions, where transit use historically has been large. If the hypothesis were true, we would find most urban areas with increasing transit usage per capita and productivity located in those regions.

Our analysis suggests that the truth of the hypothesis is associated with the size of urban regions. A comparison of the two megaurban regions (New York and Los Angeles) certainly suggests the truth of the hypothesis. However, analysis of the 7 urban regions with populations between 5 and 10 million people gives no clear indication of the truth of the hypothesis. For the 40 urban regions between 1 and 5 million people and the 31 urban regions between 500,000 and 1 million people, the hypothesis appears untrue. Of the 71 urban regions in those two categories, those that experienced transit growth during the 1990s were fast-growing regions located primarily in the West region. In the larger of those two categories, transit use per capita and transit productivity in the West region surpassed per capita usage and productivity in all other regions by 1990, and by 2000 the West surged ahead much farther in those performance measures. In the 500,000 to 1 million population category, there was little variation among the regions in 1990. By 2000, however, the West region far outpaced the others in service, ridership, and productivity.

The South, whose MSAs also grew rapidly in population during the 1990 s, did not perform as well as the West. However, there was wide variation in experience among South region MSAs, especially in the small MSA group. This variation may be important for further analysis of why transit demand increases in some growing regions but not others. We are continuing research into this question and particularly are interested in understanding whether structural differences in urban regions of the West and South can account for the difference in transit performance. Western MSAs tend to be much denser than southern MSAs, for example. Or, are there differences in the way that transit service is supplied that might explain the differences? At this point, we do not know, but from what we present here we conclude that the prevalence of old urban forms is not a prerequisite for transit growth. This analysis is based on passenger miles as the unit of transit demand; the use of unlinked trips, which we also collected, likely would change some details of the analysis but not the final conclusion. 


\section{Acknowledgments}

We are indebted to Tara Bartee and Ike Ubake in the Public Transit Office of the Florida Department of Transportation for making the FTIS available to us. We also thank Professor Albert Gan for assistance in using FTIS, and numerous transit and MPO planners for aiding our analysis. All omissions and errors remain our responsibility.

\section{References}

Cervero, R., and S. Seskin. 1995. An evaluation of the relationships between transit and urban form. Transit Cooperative Research Program Research Results Digest 7 (June). Washington, DC: Transit Cooperative Research Program.

Downs, A. 2004. Still stuck in traffic: Coping with peak-hour traffic congestion. Washington, DC: Brookings Institution Press.

Fielding, G. J. 1987. Managing public transit strategically. San Francisco, CA: JosseyBass Publishers.

Florida Department of Transportation, Public Transit Office (FDOT). 2004. Florida transit information system. From http://www.eng.fiu.edu/LCTR/Ftis/ftis.htm visited on 28 July 2004.

Hartgen, D. T., and M. L. Kinnamon. 1999. Comparative performance of major US bus transit systems, 1988-1997. 6th ed. Charlotte, NC: Center for Interdisciplinary Transportation Studies, University of North Carolina at Charlotte.

Pisarski, A. 1996. Commuting in America II. Washington, DC: Eno Foundation.

Pucher, J. 2004. Public Transportation, in Hanson, Susan and Genevieve Giuliano, eds., The geography of urban transportation. 3rd edition. New York, NY: Guilford Press.

Pucher, J., and J. L. Renne. 2003. Socioeconomics of urban travel: Evidence from the 2001 NHTS. Transportation Quarterly 57(3): 49-78.

Pushkarev, Boris, and Jeffrey Zupan. 1977. Public transportation and land use policy. Bloomington, IN: Indiana University Press.

Pushkarev, B., and J. Zupan. 1980. Urban rail in America. Bloomington, IN: Indiana University Press. 
Thompson, G. L., and T. G. Matoff. 2003. Keeping up with the Joneses: Planning for transit in decentralizing regions. Journal of the American Planning Association 69 (3): 296-312.

U.S. Census Bureau. 2000. Census 2000 redistricting data (P.L. 94 171) summary file and 1990 Census. Census 2000 PHC T 3. Ranking tables for metropolitan areas: 1990 and 2000. Table 1: Metropolitan areas and their geographic components in alphabetic sort, 1990 and 2000 population. Table 2: Metropolitan areas in alphabetic sort, 1990 and 2000. Retrieved June 2001 from $h t t p: / / w w w . c e n s u s$. gov/population/www/cen2000/phc t3.html.

U.S. Census Bureau. 2003. Metropolitan and Metropolitan Statistical Area Definitions, 2003. Retrieved February 2004 from http://www.census.gov/population/ www/estimates/metrodef.html.

\section{About the Authors}

GREGORY THOMPSON (gthompsn@garnet.acns.fsu.edu) teaches courses in transportation planning and plan evaluation and conducts research in transit policy, planning, and history in the Department of Urban and Regional Planning at Florida State University. Prior to obtaining his doctorate in social science from U.C. Irvine in 1987, Prof. Thompson worked in transit planning positions in Edmonton, Berkeley, San Diego, and Sacramento.

JEFFREY BROWN (jbrown2@fsu.edu) is an assistant professor of urban and regional planning at Florida State University. His research interests include urban transportation history, transportation finance, and public transit policy. 